\title{
RESULTATS PRELIMINAIRES OBTENUS AVEC \\ L'INTERFEROMETRE A 8 ANTENNES SUR 3 CM DE LONGUEUR D'ONDE
}

\author{
MONIQUE GUTMANN ET J. L. STEINBERG \\ Observatoire de Meudon, Meudon (Seine-et-Oise), France
}

Un interféromètre de type Christiansen fonctionne depuis Février 1958 à la Station de Nançay sur la longueur d'onde $3.2 \mathrm{~cm}$. Cet appareil comprend 8 miroirs paraboliques de diamètre $1.10 \mathrm{~m}$ régulièrement disposés \sur une poutre de $11.5 \mathrm{~m}$ à monture méridienne; le préamplificateur est monté également sur la poutre.

Le diagramme de rayonnement de cet appareil comprend 9 lobes dans le plan est-ouest, espacés d'un degré environ. Le pouvoir séparateur est de 8 minutes d'arc dans la direction est-ouest.

Il est possible de localiser les centres radio dans la direction est-ouest, et de suivre leur mouvement à travers le disque solaire. Ces régions peuvent toujours être rattachées à des centres d'activité optique.

La figure représente les trajectoires des différents centres radio à travers le disque solaire et les courbes d'égale énergie. Les chiffres indiqués donnent un ordre de grandeur de l'énergie des centres en unité arbitraire.

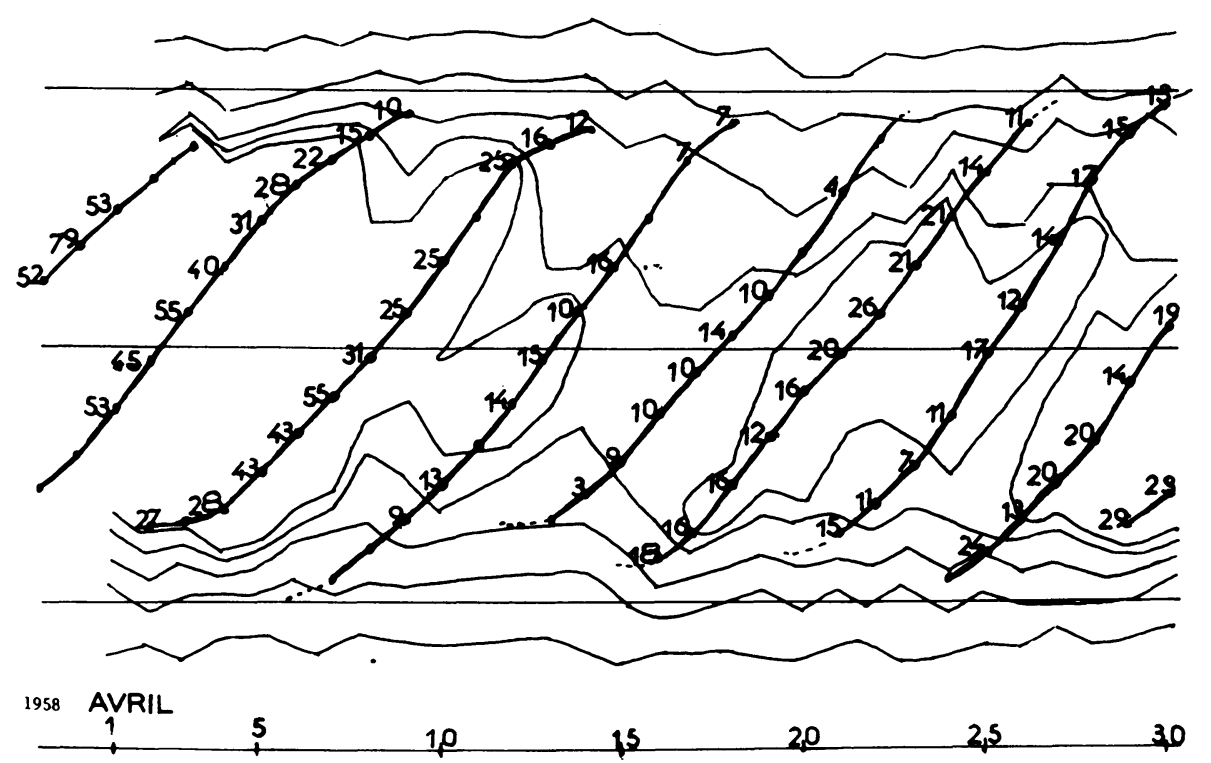

Fig. 1. Trajectoires des centres radio. 


\section{1. altitude des Centres radio}

L'altitude est certainement trop faible pour la déterminer par comparaison avec la position des centres optiques associés.

Certains centres radio apparaissant sur le limbe solaire un jour avant les plages optiques associées, il est possible pour ces centres de déterminer une altitude minima de l'ordre de $20,000 \mathrm{~km}$.

\section{DIRECTIVITE DES CENTRES RADIO}

La directivité a été étudiée en mesurant le flux de 10 sources. Nous trouvons une loi en cosinus caractéristique de l'émissivité d'une source plane. Ce résultat est en accord avec ceux trouvés par Christiansen sur $21 \mathrm{~cm}$ [1] et Vauquois [2].

\section{REFERENCES}

[1] Christiansen, W. N. Aust. J. Phys. 10, 509, 1957.

[2] Vauquois, B. Thèse, Paris, 1958. 